\title{
Making intelligent cities in Europe climate-neutral
}

\section{About the necessity to integrate technical and socio-cultural innovations}

\author{
Cordula Kropp, Institute for Social Sciences, University of Stuttgart, Seidenstr. 36, 70174 Stuttgart, Germany \\ (cordula.kropp@sowi.uni-stuttgart.de) (1) https://orcid.org/0000-0002-0373-1138 \\ Astrid Ley, Institute for Urban Planning and Design (SI), University of Stuttgart (astrid.ley@si.uni-stuttgart.de) \\ (10) $h$ ttps://orcid.org/0000-0002-7297-8214 \\ Sadeeb S. Ottenburger, Institute for Thermal Energy Technology and Safety (ITES), Karlsruhe Institute of Technology \\ (ottenburger@kit.edu) (1) https://orcid.org/0000-0001-9790-5444 \\ Ulrich Ufer, Institute for Technology Assessment and Systems Analysis (ITAS), Karlsruhe Institute of Technology \\ (ulrich.ufer@kit.edu) (1) https://orcid.org/0000-0001-5462-2903
}

Smart urban futures are currently being tested and promoted in Europe using innovative and intelligent urban technologies at different spatial scales, in individual sectors such as energy or transport, or by using specific technological innovations. However, the great transformation, though often called for and widely advocated, is yet to come. This paper discusses the necessity of promoting integrative approaches that go beyond technology-centered solutions with the aim of opening up paths towards urban climate neutrality: Precisely because urban futures are hardly predictable due to diverse and partly still hidden influencing factors, it is important to include especially socio-cultural innovations, as well as resilient technical solutions. The considerations developed in this regard conclude with a presentation of the contributions in this TATuP special topic.

\section{Auf dem Weg zu klimaneutralen und intelligenten Städten in Europa \\ Über die Notwendigkeit einer Integration technischer und sozio-kultureller Innovationen}

Smarte urbane Zukünfte werden derzeit in Europa unter dem Einsatz innovativer und intelligenter urbaner Technologien auf unterschiedlichen räumlichen Skalierungsebenen, in einzelnen Sektoren wie Energie oder Verkehr bzw. anhand spezifischer technologischer Erneuerungen erprobt und vorangetrieben. Allerdings steht die vielfach beschworene große Transformation in den Städten noch aus. Dieser Beitrag diskutiert die Notwendigkeit, über technikzentrierte Lösungen hinausgehende integrative Ansätze zu fördern, um Wege hin zur urbanen Klimaneutralität zu eröffnen: Gerade weil urbane Zukünfte angesichts vielfältiger und teils noch verborgener Einflussfaktoren kaum vorhersagbar sind, gilt es,

This is an article distributed under the terms of the Creative Commons Attribution License CCBY 4.0 (https://creativecommons.org/licenses/by/4.0/)

https://doi.org/10.14512/tatup.30.1.11 neben resilienten technischen Lösungen, insbesondere soziokulturelle Innovationen einzubeziehen. Die hierzu entwickelten überlegungen schließen mit einer Vorstellung der Beiträge in diesem TATUP-Thema ab.

Keywords: smart and intelligent cities, urban planning, climateneutrality, socio-cultural innovation, socio-technical resilience

\section{Introduction}

In Europe, as in other world regions, climate and demographic changes as well as ongoing urbanization call for reconsidering current supply structures, adapting them to the foreseeable challenges and, at the same time, developing better ones - in agreement with technological possibilities and societal expectations. Cities in particular have enormous potential in this respect. They could become pioneers of intelligent solutions for dealing with climate change thanks to their advantages of density, diverse uses of space and the innovative networks and scientific and technical institutions housed in them. However, so far, they have proved to be the main consumers of finite resources, major producers of greenhouse gases and at the same time they are particularly affected by the risks of climate change, e. g. extreme weather phenomena. The great transformation, though often called for and widely advocated, is yet to come.

What is the reason for delay, hesitancy, or inertia? Tailwinds from international agreements are certainly not lacking. In particular, the United Nations' 2030 Agenda and the Paris Agreement point to the specific role of cities in achieving ambitious climate and sustainability goals. However, cities are often not able to fulfil the expectations placed on them. One of the key challenges is the design of integrated approaches. Cities need in- 
novations that resonate with local specificity, promote diversity and tolerance and that proceed in a socially acceptable manner. So, is too little attention being paid to the economic, political and socio-cultural conditions of climate neutrality in the technology focused discussion? Is it not possible to link the technological perspectives with the social conditions in cities and their architectural and infrastructural heritage? Is there a lack of suitable forms of co-design to initiate the necessary changes towards intelligent, climate-neutral and livable cities?

\section{Intelligent, smart, and climate-neutral - an evident connection?}

Research funding programs as well as communications from science and journalism increasingly convey a causal link between smart technologies and the vision of climate-neutral and intelligent cities (EC-DGRI 2020; Lombardi et al. 2012; Yigitcanlar et al. 2019). As the planning and implementation of smart cities occur in a mode of increased acceleration in light of the urgency stressed in all climate change scenarios, it is one of the tasks of technology assessment to critically reflect on and accompany these causal assumptions between smart technological innovation and climate neutrality as well as sustainability.

Behind the connection of both concepts are, on the one hand, perceived technical necessities, such as load balancing in electricity grids that are fed by a multitude of highly fluctuating sources of renewable energy, some of which come from private households. On the other hand, the efficiency paradigm of intelligent process management offers big promises to cities: to optimize urban resource consumption, or to enhance the mobility of people and goods in a way that increases sustainability and reduces $\mathrm{CO}_{2}$ emissions without requiring drastic changes in everyday rou- et al. 2013; Sonnberger and Groß 2018; Kropp 2019; Santarius et al. 2020; Hofmann et al. 2021). Moreover, the so-called intelligent solution approaches, such as those of the smart city, raise critical issues of data protection, or of the guarantee of distributive justice and long-term shaping of democracy (Bauriedl and Strüver 2018), which have induced a change of course in some cities, for example in the former pioneering city of Barcelona (Charnock et al. 2021; de Hoop et al. 2019). What is needed, therefore, is an integration of technical and socio-cultural innovation approaches, as demonstrated by the papers published in this TATuP special topic.

\section{Guiding principles for the city of the future}

Once again, the discussion in urban planning is about how the transformation of cities can succeed. Already during early industrialization and well into the $20^{\text {th }}$ century, a modern sewerage system, access to the electricity grid and a de-densification of the built city were considered parameters to counteract the ills and rampant diseases in cities. Aspects of hygiene, safety and the growing demand for climate neutrality or climate change adaptation are providing impetus today - this time for the conversion to smart or intelligent cities. Both planning visions for the city of the future are based on technical and functional optimization. However, a purely technical understanding of innovation from an engineering perspective comes with the risk of being too narrow and one-sided, thus raising criticism that "generally, there is no room for another form of innovation, one that would be aesthetically or even socially motivated." (Rauterberg 2020, translation by the authors) Arguing along similar lines, the German Advisory Council on Global Change (WBGU) does

\section{Is it possible to manage the great transformation technically without causing profound socio-cultural changes?}

tines or even a painful renunciation on the part of the citizens. In fact, the narrative of technical efficiency is easier to communicate than the need for a fundamental change in lifestyles in terms of sufficiency. However, is it possible to manage the great transformation technically without causing profound cultural changes that might bring social, political or economic upheavals?

The promise of technical efficiency is contradicted by the fact that intelligent systems implemented in cities so far often remain behind the sustainability expectations placed in them. Often, expected efficiency gains can only be realized in very specific use scenarios and still they trigger rebound effects. Also, producing and implementing solutions for technical efficiency mostly consumes non-renewable resources, thus leading to more emissions than can be saved, at least in the medium term (Schneidewind not link the necessary urban transformation to a conventional 'business as usual' of resource- and emission-intensive neighborhoods and cities, but sees the 'transformative power of cities' in newly developed guiding principles and strategies for urbanization that promote quality of life without further burdening the environment (WBGU 2016).

But what constitutes quality of life in cities? What are appropriate technologies and applications that citizens want? Who decides? Smart city projects are being tested all over the world, often supported by large public funding programs and entrepreneurial engagement. Generally, the starting point is technical and economic feasibility, since IT providers have at least a vague idea of the potential that digitalization holds for urban development and infrastructure management. But that also means 
that they orient themselves along existing and available experiences, thus creating path dependencies. In the long term, future urban and infrastructure planning will be determined by today's decisions. With regard to urban digitalization this may lead to future dependencies on externally contracted service providers, to limited access to relevant planning data collected by and then locked in within these providers, or to reduced digital sovereignty of municipalities and limited ability to define locally appropriate and sustainable pathways (Deutscher Städtetag 2020). Only a few municipalities find the courage to explore together with their citizens what "smart city" or "intelligent city" can and should mean for them in the face of the major technology driv- oriented spectrum, since the 1990s they have tended to arise from the neoliberal project of economizing all areas of life. In terms of the urban context, this inversion of ideologies corresponds to the change from the political model of the 'social city' to that of the 'entrepreneurial city' over the past thirty years (Berger and Schmalfeld 1999).

Building on the creative city as an urban planning model of the 2000s, the implementation of intelligent or smart urban technologies and services was considered at its early stages by both companies and policy makers as a project for postindustrial revitalization that seemed to offer a way out of urban economic and municipal budgetary crises (Harrison and Abbott Donnelly

\section{The path towards urban climate neutrality seems to require further integration of technological, political, cultural and social innovations.}

ers: a pioneer in this respect is the small city of Soest in North Rhine-Westphalia (Stadt Soest 2021). One result of their diverse participation process is that the city's residents only want to embrace smart solutions that are not only digital but also sustainable.

Considering this, a closer connection of technological, political, cultural and social innovations seems necessary for cities to follow the path towards urban climate neutrality. As a consequence, socio-cultural dimensions of cities do not only appear as relevant factors for diffusion, acceptance and application of innovative technologies, and cultural skills do not only constitute adaptive capacities to changing market and environmental conditions. In fact, it would be much more important to constructively integrate these dimensions into local innovation cultures for adequate solutions that meet local needs, e. g. in citizen-oriented living labs (Schneidewind and Scheck 2013) or in social movements for urban transformations 'from below' (Ufer 2018). Such settings show how innovation, as a recursive process, is based on complex social relations, collective action and creative abilities to recombine and reinterpret known elements (Friedman 2001). Innovation is not a linear process between technical invention, social diffusion and cultural change (Ufer and Hausstein 2021). The great challenge is to connect the lived urban space of socio-cultural change with the transformative forces of smart urban technologies.

\section{Integrating technical and socio-cultural innovations}

To this end, it is interesting to take a look at the changing ideological settings of scientific and policy discourses: whereas technological determinist positions were formed with the goal of social progress during the 1970 s and 1980s from a more left-wing
2011, pp.4-5). Extending this close tie between intelligent urban design and economic priorities, in recent years a techno-determinist discourse has been linking intelligent technologies to both economic and ecologic agendas. It comes with the promise to contribute to urban sustainability, but often fails to make explicit the extent to which this would also require alternative patterns of thought, action and decision-making. Among some actors, this discursive reorientation has resulted in a neo-modernist enthusiasm for the technical malleability of urban society and culture that has not been observed for quite some time.

Technological determinism is based on the assumption that unsustainable contradictions between societal resource consumption and emissions on the one hand, and the regenerative and absorptive capacity of the biosphere on the other, can be solved or overcome through technological innovation. Such findings are contrasted by analyses of, for example, the overuse of natural resources due to global inequality, missing socio-technical qualities in implementations and infrastructures, counterproductive regulatory approaches and missing incentives for action, as well as a lack of problem awareness. Even more fundamentally, dynamics of social inequality and ecological exploitation are also described as being reproduced through technical innovation itself, because they are embedded but hidden properties of socio-technical systems and their scripts for action (Hornborg 2014). This calls for changes that go beyond purely technical innovations. For this purpose, it seems advisable to bring into intelligent cities also the intelligence of those who are familiar with local specificity and concrete conditions and know, for example, the potentials and pitfalls associated with local supply structures, sustainable mobility services or inclusive uses of public spaces. Algorithmic systems intend to address such issues of place specificity, but their operations remain bound to stochastic rationalities in which the lived urban space with its place 
bound "idiosyncrasy" (WBGU 2016, p. 153) is always subordinated to the computed mean value of the digital space.

\section{Sustainability and the resilient handling of uncertainties}

At present, systemic supply risks in a future smart urban world, in which networking, automation and complexity of socio-technical systems have increased, can hardly be quantified reliably (Helbing 2013). Part of this uncertainty is that the long-term steady planning and reliable operation of sustainable energy systems, which depend on volatile renewable decentralized feed-in, are based, among other things, on regional climate or weather forecast models. However, the further we look into the future, the more uncertain these are (Aloul et al. 2012). Thus, for example, an additional demand for electricity for the use of cooling systems associated with a heatwave (Panteli et al. 2015) can lead to supply bottlenecks and overloads of distribution and transmission grids and ultimately to large-scale blackouts. The resulting failure cascades in highly networked and automated or electrified systems (Buldyrev et al. 2010) may lead to considerable supply failures of systemic proportions and significantly reduce the "performance" of a smart city.

Future risks and uncertainties about possible damages, their probability of occurrence and impacts as a consequence of technological transformations complicate decisions about today's investments and strategies to safeguard the security of supply. For example, today's decisions on the dimensions of energy storage and other grid capacities could prove inadequate and lead to more frequent supply failures in the future than expected. These that such acutely critical situations require blackout prevention measures to be implemented within a short period of time, a differentiated discussion on the role of consumers with regard to new, smart and elastic management concepts is necessary. Demand-side management (DSM) approaches seem to answer to such new needs for system relief in different situations by conferring to consumers partial responsibility for the system, usually through economic incentives. However, DSM reveals major shortcomings in acutely critical situations, e. g. if electric cars are not charged economically and rationally at the lowest price, but if instead, in the face of an imminent power shortage, a large number of users would charge at the same time and thus overload the grid. Furthermore, DSM may lead to socially unjust supply patterns (Ottenburger et al. 2020), as individual consumers in smart grids could receive targeted supply in the event of general power outages. What would seem to be justified in the case of critical infrastructure, e. g. hospitals, could call into question the legal principle of equal treatment of services of general interest in the case of privileging individual private households.

Consequently, building resilient, intelligent, and smart cities is a cross-domain challenge precisely because it involves epistemic uncertainty. Concerning future energy scenarios, this means not only that the future is of course always uncertain, but also that the prospect of climatic and other systemic tipping points makes linear foresight of developments impossible. Because of this epistemic uncertainty, the currently prevailing rigid supply paradigm must be questioned with regard to future sustainable energy systems in smart cities. Moreover, it is important to systematically investigate the emergent paradigm of flexibility not only with regard to technical feasibility on the generation

\section{Only a holistic view of resilience and sustainability makes it possible to turn smart and intelligent cities into a long-term success story.}

outages do not necessarily have to be large-scale, but they could occur in many low- or medium-voltage zones of the distribution grids thus affecting the willingness of users to switch to sustainable forms of energy supply. Consequently, questions about the socio-technical design of future supply systems are of great relevance and require systemic answers that encompass the engineering design of smart grid structures, the regulatory adaptation of standards, the communication of necessary user knowledge and sensitivity for cultural values as well as for hierarchical access limitations.

This is illustrated by the example of a successful cyber attack. A cyber attack can cause a spontaneous outage of important generation capacities, so that grid operators are not able to ensure the stability of the grid on their own. Given the fact and consumer side but also to address social aspects such as distributive justice or democratization of energy via neighborhood power feed-in and neighborhood emergency storage.

The sustainable use of technical possibilities requires not only considering the robustness of individual sub-systems but also taking into account the admission of insufficient knowledge about intended and unintended effects and side-effects, future risks and the still unresolved questions of the conditions for a successful transformation. All this necessarily relies on developing socio-technical concepts for co-design that respects the specificities of urban space using both social and technical intelligence as well as cultural contexts. In this sense, only a holistic view of resilience and sustainability makes it possible to turn smart and intelligent cities into a long-term success story. 


\section{Contributions in this TATuP special topic}

Currently, smart urban futures are being tested at different scaling levels such as buildings, districts, cities or regions, in individual sectors such as energy or transportation, or with regard to specific technological innovations such as lamp posts equipped with sensors (smart poles). Smart pilot cities, which have so far been created in only a few places around the world, also have a laboratory character to test smart urban design for wider dissemination. In this context, Claudia Mendes' contribution asks about the 'replication rationale' in the European Union (EU) funding programs for smart cities. She concludes that the technical replicability of local smart innovations in 'follower cities' is formulated as a goal in policy papers, but that actual cooperation practice is rather about knowledge exchange than technology exchange. At the same time, the author points out that the 'replication rationale' contributes to an increasingly technology-oriented urban planning and opens up a subsidiary level for EU governance via the regulation of technologies.

In their comparative study between the cities of Munich and Barcelona, Alexander Wentland and Manuel Jung address scalability and replication expectations regarding smart solutions at neighborhood level. The focus here is on dimensions of temporality with regard to the implementation, realization and dissemination of projects for sustainable urban transport transformation. The authors present asynchronies between different urban time scales as a key challenge for successful urban transformation, e. g. in relation to the slow adaptation of mobility routines in the neighborhoods and the limited duration of third-party funded projects.

Based on the example of the city of Stuttgart and the surrounding region of the Neckar Valley, Raphael Dietz et al. point at the urban planning potentials and challenges that may arise in the areas freed up by the energy transition. Their contribution shows several possibilities for developing the Neckar river bank as an attractive settlement area on brownfield land, but also points out quite legitimate reservations and obstacles (inertial forces). Using the method of scenario-based mission statements, the authors present an approach for negotiating stakeholder positions on the basis of urban morphology and discuss it as a contribution to the successful design of such large-scale urban transformation projects.

Daniel Bell et al. investigate attitudes towards living comfort in energy flexible buildings in Vienna on the scale of individual buildings, both on the part of the residents and on the part of the planners. A contribution not only to emission reduction but also to the energy transition is hoped for from energy flexible buildings equipped with intelligent heating and cooling technology, as they could themselves serve as energy storage in the case of volatile energy supply. Living comfort is thus an important parameter for testing the acceptance of this approach to the energy transition and to climate neutrality.

Sustainably generated electricity and heat are essential factors on the way to smart and climate-neutral cities, but the heat aspect is usually only treated as secondary. Comparing the city of Essen and the district of Gießen, André Ortiz et al. therefore, address how existing heat registers can be made more dynamic by means of innovative software that can contribute to urban heat and energy solutions in dealing with volatile supply structures from renewable energies. Their study shows that a high degree of collaboration between the different actors of urban heat supply will be necessary for the implementation.

Finally, Helene Wichmann's contribution explores the transformational potentials and challenges of urban beekeeping for climate-neutral cities with a view to linking social innovations, such as communal management of beehives, with technological innovations, such as agro-informational applications of the Internet of Things (IoT). Precision beekeeping can help overcome some of the challenges faced by young urban beekeepers in particular but it does not always correspond to their ecological motivations when it follows agro-industrial rationales. In light of this ambiguity the author also points to a rising danger to urban biodiversity when the trend to technologically supported honey bee keeping exacerbates the food competition that threatens wild bees.

\section{Funding declaration}

The research contribution by Cordula Kropp to this article is supported by the Deutsche Forschungsgemeinschaft (DFG, German Research Foundation) under Germany's Excellence Strategy - EXC 2120/1-390831618.

\section{References}

Aloul, Fadi; Al-Ali, Abdulrahman; Al-Dalky, Rami; Al-Mardini, Mamoun; El-Hajj, Wassim (2012): Smart Grid security. Threats, vulnerabilities and solutions. In: International Journal of Smart Grid and Clean Energy 1 (1), pp. 1-6. https://doi.org/10.12720/sgce.1.1.1-6

Bauriedl, Sybille; Strüver, Anke (eds.) (2018): Smart City. Kritische Perspektiven auf die Digitalisierung der Städte. Bielefeld: transcript.

Berger, Olaf; Schmalfeld, Andreas (1999): Stadtentwicklung in Hamburg zwischen "Unternehmen Hamburg“ und „Sozialer Großstadtstrategie“. In: Jens Dangschat (ed.): Modernisierte Stadt, gespaltene Gesellschaft. Ursachen von Armut und sozialer Ausgrenzung. Opladen: Leske+Budrich, pp. 317-341.

Buldyrev, Sergey; Parshani, Roni; Paul, Gerald; Stanley, Eugene; Havlin, Shlomo (2010): Catastrophic cascade of failures in interdependent networks. In: Nature 464 (7291), pp. 1025-1028. https://doi.org/10.1038/nature08932 Charnock, Greig; March, Hug; Ribera-Fumaz, Ramon (2021): From smart to rebel city? Worlding, provincialising and the Barcelona Model. In: Urban Studies 58 (3), pp. 581-600. https://doi.org/10.1177/0042098019872119

de Hoop, Evelien; Smith, Adrian; Boon, Wouter; Macrorie, Rachel; Marvin, Simon; Raven, Rob (2019): Smart urbanism in Barcelona. A knowledge politics perspective. In: Jens Stissing Jensen, Matthew Cashmore and Philipp Späth (eds.): The politics of urban sustainability transitions. Knowledge, power and governance. London: Routledge, pp. 33-52.

Deutscher Städtetag (2020): Digitale Souveränität von Kommunen stärken. Diskussionspapier des Deutschen Städtetags. Berlin: Deutscher Städtetag. Available online at https://www.staedtetag.de/files/dst/docs/Publikationen/ Positionspapiere/2020/digitale-souveraenitaet-diskussionspapier.pdf, last accessed on 29. 01.2021. 
EC-DGRI - European Commission, Directorate General for Research and Innovation (2020): 100 climate-neutral cities by 2030 - by and for the citizens. Interim report of the mission board for climate neutral and smart cities. Luxembourg: Publications Office of the European Union.

Friedman, Jonathan (2001): The iron cage of creativity. An exploration. In: John Liep (ed.): Locating cultural creativity. London: Pluto Press, pp. 46-61. https://doi.org/10.2307/j.ctt18fs9q6.7

Harrison, Collin; Abbott Donnelly, Ian (2011): A theory of smart cities. In: Proceedings of the $55^{\text {th }}$ Annual Meeting of the International Society for the Systems Sciences, Hull, UK, 17.-22.07.2011, pp.521-535. Available online at https://journals.isss.org/index.php/proceedings55th/article/view/1703/572, last accessed on 29.01.2021.

Helbing, Dirk (2013): Globally networked risks and how to respond. In: Nature 497 (7447), pp. 51-59. https://doi.org/10.1038/nature12047

Hofmann, Josephine; Ricci, Claudia; Ansu-Holz, Doris (2021): IT und Nachhaltigkeit. Eine Einführung. In: HMD Praxis der Wirtschaftsinformatik 58 (1), pp. 6-23. https://doi.org/10.1365/s40702-020-00692-x

Hornborg, Alf (2014): Technology as fetish. Marx, Latour, and the cultural foundations of capitalism. In: Theory, Culture \& Society 31 (4), pp. 119-140. https://doi.org/10.1177/0263276413488960

Kropp, Cordula (2019): Nachhaltige Innovationen. In: Birgit Blättel-Mink, Ingo Schulz-Schaeffer and Arnold Windeler (eds.): Handbuch Innovationsforschung. Wiesbaden: Springer Fachmedien, pp. 1-18. https://doi. org/10.1007/978-3-658-17671-6_50-1

Lombardi, Patrizia; Giordano, Silvia; Farouh, Hend; Yousef, Wael (2012): Modelling the smart city performance. In: Innovation - The European Journal of Social Science Research 25 (2), pp. 137-149. https://doi.org/10.1080/13511610.201 2.660325

Ottenburger, Sadeeb Simon et al. (2020): A novel optimization method for urban resilient and fair power distribution preventing critical network states. In: International Journal of Critical Infrastructure Protection 29, p. 100354. https://doi.org/10.1016/j.ijcip.2020.100354

Panteli, Mathaios et al. (2015): Impact of climate change on the resilience of the UK power system. In: Proceedings of the IET International Conference on Resilience of Transmission and Distribution Networks. Birmingham, UK: Institution of Engineering and Technology. https://doi.org/10.1049/ cp.2015.0878

Rauterberg, Hanno (2020): „Eine Architektur des Ankommens“. In: DIE ZEIT, 07. 02.2020, p. 46.

Santarius, Tilman; Pohl, Johanna; Lange, Steffen (2020): Digitalization and the decoupling debate. Can ICT help to reduce environmental impacts while the economy keeps growing? In: Sustainability 12 (18), p. 7496. https://doi.org/10.3390/su12187496

Schneidewind, Uwe; Zahrnt, Angelika; Zahrnt, Valentin (2013): Damit gutes Leben einfacher wird. Perspektiven einer Suffizienzpolitik. Munich: oekom verlag.

Schneidewind, Uwe; Scheck, Hanna (2013): Die Stadt als „Reallabor“ für Systeminnovationen. In: Jana Rückert-John (ed.): Soziale Innovation und Nachhaltigkeit. Perspektiven sozialen Wandels. Wiesbaden: Springer vS, pp. 229-248.

Sonnberger, Marco; Gross, Matthias (2018): Rebound effects in practice. An invitation to consider rebound from a practice theory perspective. In: Ecological Economics 154, pp.14-21. https://doi.org/10.1016/j.ecolecon.2018.07.013

Stadt Soest (2021): Soest Digital. Available online at https://digital-soest.de/, last accessed on 28. 01.2021.
Ufer, Ulrich (2018): Practicing urban transformation. Places of solidarity and creative traditionalism in transatlantic comparison. In: City \& Society 30 (3), pp. 318-340. https://doi.org/10.1016/j.ecolecon.2018.07.013

Ufer, Ulrich; Hausstein, Alexandra (2021): Anthropology of and for innovation. In: Gerald Gaglio, Benoît Godin and Dominique Vinck (eds.): Handbook of alternative theories of innovation. Cheltenham, UK: Edward Elgar Publishing, in press.

WBGU - Wissenschaftlicher Beirat der Bundesregierung Globale Umweltveränderungen (2016): Der Umzug der Menschheit. Die transformative Kraft der Städte. Berlin: WBGU.

Yigitcanlar, Tan; Kamruzzaman, Md.; Foth, Marcus; Sabatini-Marques, Jamile; da Costa, Eduardo; Ioppolo, Giuseppe (2019): Can cities become smart without being sustainable? A systematic review of the literature. In: Sustainable Cities and Society 45, pp. 348-365. https://doi.org/10.1016/j. scs.2018.11.033

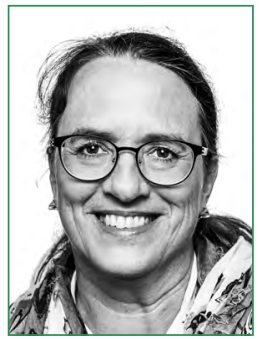

\section{PROF. DR. CORDULA KROPP}

holds the Chair of Sociology of Technology, Risk and Environment and is Director of the Centre for Interdisciplinary Risk and Innovation Research at the University of Stuttgart (ZIRIUS). Her research focuses on socio-technical transformation processes and their participation-oriented and sustainable design.

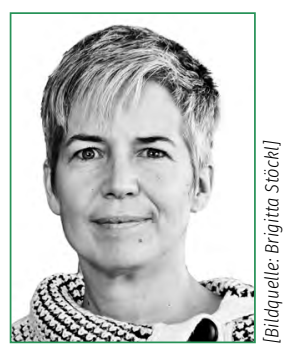

\section{PROF. DR. ASTRID LEY}

is Director of the Urban Design Institute at the University of Stuttgart. As a professor of International Urbanism, her teaching and research focus on urban transformation towards sustainability; in particular on questions of informal urban development, governance and housing provision in the context of cities in the Global South.

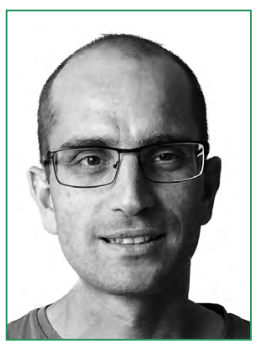

\section{DR. SADEEB SIMON OTTENBURGER}

is leading resilience research at the Institute for Thermal Energy Technology and Safety (ITES) at the Karlsruhe Institute of Technology (KIT). His research is in the field of smart resilience engineering and he develops concepts of sustainable, adaptive and resilient supply systems.

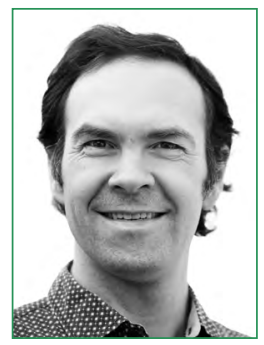

\section{DR. ULRICH UFER}

is Senior Researcher at the Institute for Technology Assessment and Systems Analysis (ITAS) at the Karlsruhe Institute of Technology (KIT). As an anthropologist and historian his research includes socio-cultural as well as conceptual aspects of urban transformation and innovation. 